\title{
ฟิธ \\ Os primórdios da primeira lei dos movimentos planetários na carta de 14 de dezembro de 1604 de Kepler a Mästlin
}

Claudemir Roque Tossato

Nos últimos dias de 1604, Kepler escreve para seu mestre Mästlin uma carta na qual solicita seu parecer sobre a correta forma orbital do planeta Marte, trabalho que vinha desenvolvendo desde 1601, alguns meses após a morte de Tycho Brahe e a admissão de Kepler como matemático imperial da corte de Rodolfo II em Praga, cargo que pertencera anteriormente a Brahe. Essa carta pode ser inicialmente entendida como apenas uma espécie de "cobrança" por parte do discípulo com o objetivo de romper com o comportamento reticente do mestre. Afinal, Mästlin manteve-se calado sobre as investigações físicas propostas por seu antigo aluno por um período considerável de tempo. Com efeito, Mästlin não respondia a Kepler desde 1599, só voltando a escrever-lhe em 28 de janeiro de 1605 , após mais de cinco anos sem mandar qualquer resposta às insistentes cartas enviadas por Kepler.

Além desse aspecto pessoal, a carta de Kepler traz, para o leitor interessado no desenvolvimento de seu pensamento e no processo de formação da astronomia moderna, uma primeira formulação interessante de um dos estágios do processo de obtenção daquela que se passou a chamar "a primeira lei dos movimentos planetários". Como se sabe, essa lei afirma que os planetas movem-se em órbitas elípticas em torno do Sol, que ocupa um dos dois focos da elipse orbital. Esse estágio encontra-se no segundo parágrafo da carta, no qual Kepler relata alguns dos resultados que tinha obtido até esse momento, bem como as dificuldades de adequar os movimentos planetários representados com o expediente do epiciclo' ${ }^{1}$ a suas exigências físicas, pois isso contrariava os dados observacionais de Tycho Brahe. A importância da carta está, como veremos abaixo, em apontar para a primeira etapa da obtenção da forma elíptica, isto é,

1 O leitor encontrará depois das notas à tradução da carta um pequeno glossário sobre os termos técnicos envolvidos na discussão. 
na suposição de que a órbita de Marte, para corresponder aos dados de Brahe e aos princípios físicos adotados por Kepler para a astronomia, tem uma forma oval, conduzindo à conseqüente negação do axioma platônico, segundo o qual os movimentos planetários devem ser descritos por meio de movimentos circulares e uniformes ou por meio da combinação de movimentos circulares e uniformes.

\section{O GONTEXTO DA GARTA}

A carta apresentada adquire importância histórica por ser um dos primeiros documentos contendo a exposição de que o axioma platônico, quando visto sob a ótica da realidade, isto é, quando se considera o corpo físico do Sol como centro dos movimentos planetários, apresenta problemas para a representação matemática desses movimentos, pois tal axioma não é corroborado pelos dados de Brahe.

O peso histórico dessa crítica extrapola o nível da astronomia matemática do início do século dezessete, abarcando a própria concepção de mundo desse período. Acreditar que o mundo celeste contém movimentos circulares e uniformes é o mesmo que acreditar, no final do século XVI, que os objetos caem porque são pesados. Isto é, a crença nos movimentos circulares e uniformes é a expressão da natureza dos movimentos celestes; não havia razão para supor que eles fossem de outro modo; eles são tidos como os únicos movimentos dignos do mundo celeste, mundo esse perfeito, incorruptível, não sujeito às mudanças sempre presentes no mundo físico. Se, aqui na Terra, vivemos num mundo em que as alterações de estado ocorrem freqüentemente (um homem se apresenta num determinado momento como saudável e, num outro, adoece; a água pode ser num momento líquida, em outro, gasosa, e num outro, sólida; um objeto, como uma cadeira, pode ser transformado em outro objeto, uma mesa, por exemplo), indicando a falta de permanência dos fenômenos terrestres, um eterno vir a ser, com poucos momentos de estabilidade, o mesmo não é notado no céu, pois nesse não há outra alteração além de seu movimento local. Desde que o homem começou a observar o céu, este se apresentou com o mesmo comportamento: ${ }^{2}$ os astros movem-

\footnotetext{
2 Não podemos, para visualizar a concepção de mundo do período que vai dos antigos até Kepler, esquecer que os fenômenos celestes observados eram poucos nesse período em relação aos de hoje em dia, isto é, mínimas alterações foram notadas no céu por mais de 5000 anos (data das primeiras observações dos babilônios, que são os primeiros registros que temos sobre as ocorrências celestes). Isso se explica pelo fato de que as durações dos fenômenos celestes são de ordem maior do que os daqui, na Terra; cinco mil anos é um valor muito pequeno, ínfimo, em relação ao valor de tempo dado à precessão dos equinócios - estimado em aproximadamente 25800 anos -, por exemplo,
} 
se regular e aparentemente em torno de nossa Terra (o Sol, a Lua e as estrelas fixas se apresentam, regularmente, nos "lugares" que se espera que estejam, não se notando alterações profundas em seu comportamento); nunca tinha sido notado, com pequenas exceções, coisas tais como cometas e novas e supernovas, ${ }^{3}$ que podem ser vistas como alterações acidentais nos céus. Ora, se o mundo celeste não está sujeito às alterações que se notam aqui na nossa moradia, então, qual a razão, seja ela religiosa, cultural ou mesmo epistemológica, para se afirmar que tanto o céu quanto a Terra têm a mesma natureza? No modo de ver dos antigos, poucas ou nenhuma, sendo mais coerente e natural afirmar que os movimentos do mundo celeste são naturalmente circulares e uniformes, pois tais movimentos indicam o estado de permanência dos fenômenos celestes.

Aimagem de mundo greco-medieval, e mesmo a do Renascimento, alicerçou-se nessa concepção dualista entre os mundos celeste e terrestre. $\mathrm{O}$ axioma se estabeleceu tão firmemente, que nenhum astrônomo antes de Kepler o questionou, ou como expõe Hanson:

Nunca se chegou a pôr em dúvida esse princípio [circularidade e uniformidade] durante os 2000 anos de astronomia computacional técnica. Copérnico não o fez, Ptolomeu não o poderia ter feito. Como alguém poderia colocar em dúvida tal princípio dado o contexto intelectual em que se movia o pensamento antigo? As razões dessa aceitação completa eram em parte observacional e em parte filosófica, estando fortemente reforçadas por outros fatores estéticos e culturais. (Hanson, 1985, p. 225)

utilizados hoje em dia em astronomia. Aliado a isso, está o fato do homem não ter, até o final do século dezesseis e início do dezessete, com o uso do telescópio de 1609, instrumentos que alargassem a sua visão sobre o cosmo. Se hoje em dia a astronomia utiliza-se de uma grande gama de instrumentos de aproximação para a visão (como os rádios telescópios), ou de técnicas para a compreensão da constituição física do céu, e mesmo o envio de naves espaciais para a coleta de materiais a outros planetas, o que tínhamos na época de Kepler eram apenas as observações dos movimentos dos astros e observações de fenômenos (eclipses, oposições, cometas etc) e, em alguns momentos, observações de novas e supernovas, como a de Brahe de 1572. Em outros termos, dada a lentidão, em relação aos fenômenos terrestres, dos fenômenos celestes e da falta de condições técnicas para o seu estudo, era normal e intelectualmente aceitável considerar que o céu era imutável, não apresentando, seja no passado, no presente ou no futuro nenhuma mudança significativa em sua constituição natural.

3 Nova é uma estrela que subitamente aumenta a sua luminosidade em torno de 10 mil a 100 mil vezes. Esse aumento faz que ela se apresente mais luminosa no céu por um período de horas ou de um dia. Uma supernova é uma estrela que adquire repentinamente um aumento exagerado de luminosidade e, depois, começa a enfraquecer essa luminosidade lentamente; na verdade, uma supernova é uma estrela que explode, por atingir um estágio de envelhecimento avançado. 


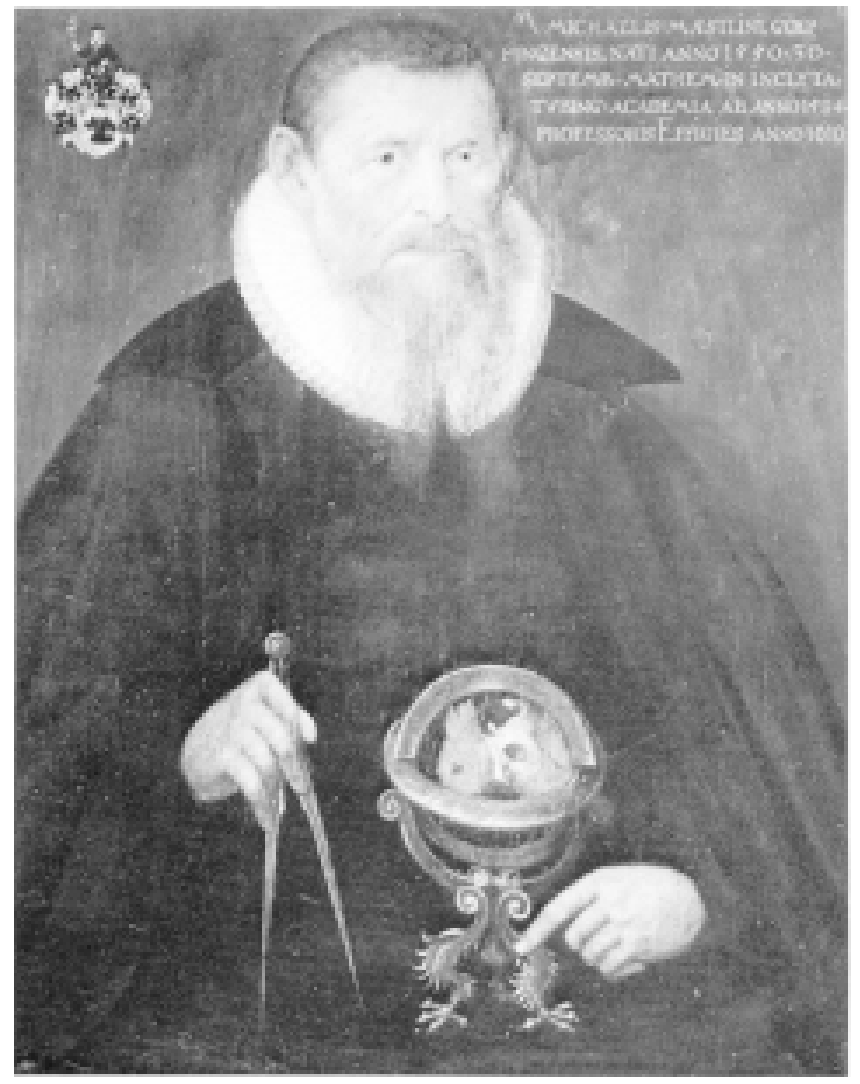

Claudemir Roque Tossato

\begin{abstract}
Michael Mästlin foi o principal
mestre de Kepler, iniciando-o nas

novas propostas copernicanas.
\end{abstract}

A visão de que o cosmo é composto de dois mundos distintos imperou em todas as formas de pensamento. Na científica, como no caso da astronomia e da cosmologia, foi utilizada para a confecção de modelos descritivos dos movimentos planetários e na elaboração de explicações do cosmo; na religião, principalmente para o mundo judaico-cristão, foi utilizada para embasar uma visão moral, pois preenche os preceitos básicos de um mundo hierarquicamente ordenado: o mundo terrestre imperfeito, no qual o mal pode imperar, e o mundo celeste perfeito, destinado aos bem-aventurados na outra vida; na mágico-astrológica, serve de base para a tese central da influência dos astros sobre os acontecimentos terrestres e os destinos humanos.

Porém, se o Sol, a Lua e as estrelas fixas mantêm movimentos plenamente, ou quase plenamente, circulares e uniformes, o mesmo não se dá com os planetas, ${ }^{4}$ pois sempre mostram "fugas" desses movimentos. Suas órbitas não são observadas nem como plenamente circulares, pois mostram paradas, retrocessos e pequenas voltas em seus trajetos siderais, nem como plenamente uniformes, pois apresentam variações de velocidades. Nesse sentido, o axioma platônico serve como parâmetro para a deter-

4 O próprio significado de planeta para os gregos é "errante”, isto é, o astro que não apresenta, pelas observações astronômicas, movimentos circulares e uniformes. 
minação dessas fugas ao princípio condicionador de circularidade e uniformidade. A função dos astrônomos, após a aceitação do axioma como natural e inconteste, foi a de adequar os movimentos observados à circularidade e à uniformidade, donde temos os significados dos termos "excêntrico", "epiciclo", "deferente" tão presentes na carta de Kepler a Mästlin. Como ponto importante do uso dessas técnicas, o centro físico de movimentos (que antes de Copérnico, era a Terra) foi paulatinamente desconsiderado, isto é, se para adequar os movimentos observados ao axioma era necessário, como na maioria das vezes, considerar um centro não físico, mas matemático, o astrônomo assim o faria; com isso, a astronomia de posição acabou construindo modelos que empregavam um centro não físico de movimentos. Os astrônomos antigos e medievais foram os grandes executores na técnica de expressar os dados observacionais na forma de curvas que representam a circularidade e a uniformidade: qualquer conjunto de dados observacionais poderia ser decomposto nas suas partes elementares e transformado em qualquer tipo de figura geométrica que se desejasse: poder-se-ia representar os movimentos em formas triangulares, quadradas, elípticas, retangulares, espiraladas etc. Sendo assim, foi relativamente "fácil" poder, mediante as técnicas matemáticas desenvolvidas, expressar as irregularidades dos movimentos em termos de movimentos circulares e uniformes.

Mas se havia facilidade em expressar os movimentos nas mais diversas formas geométricas, isso trouxe, como conseqüência, a possibilidade de expressar os mesmos movimentos com as mais variadas técnicas possíveis, isto é, obtinha-se os mesmos resultados (entendidos como a projeção dos futuros movimentos que os planetas iriam ter, os seus posicionamentos ao longo da eclíptica) usando tanto a técnica do excêntrico como a técnica do epiciclo com deferente, ou, ainda, a técnica do duplo epiciclo. Mas, nesses casos, o que expressa a realidade do mundo celeste? Qual é a técnica que se refere à ontologia celeste? Nenhum astrônomo prático, ou mesmo nenhum cosmólogo, soube responder essas questões, de maneira que tivemos, por mais de 2000 anos, a prevalência da equivalência observacional em astronomia, ignorando-se qual técnica podia ser melhor associada à realidade do mundo celeste.

Na verdade, o próprio astrônomo prático estava consciente do seu papel puramente calculatório, instrumental, não lhe cabendo falar sobre a realidade do mundo celeste, pois essa era a função do filósofo natural, mais especificamente do cosmólogo. Este, contudo, também não saberia argumentar se, de fato, o mundo celeste continha epiciclos, deferentes, concêntricos etc. Antes de Copérnico, Kepler e Galileu, os cosmólogos elaboravam sistemas explicativos que expressavam os corpos celestes por meio de esferas encaixadas uma nas outras, propostas e desenvolvidas originariamente por Eudoxo e Aristóteles, de modo a garantir a distinção entre os mundos celeste e terrestre, uma espécie de "maquinaria” cósmica. Dado esse contexto, o astrônomo 
restringiu-se a fazer astronomia preditiva, catalogando as melhores posições possíveis, sem tratar das causas físicas envolvidas nos movimentos planetários, por outro lado, o cosmólogo procurou elaborar sistemas explicativos, mas obtendo pouco sucesso, quando da aplicação desses sistemas, no que concerne às predições.

Uma vez que os mundos eram distintos, também eram os métodos. Para o mundo terrestre, era possível discutir as coisas por meio de explicações, isto é, era possível tentar obter as causas genuínas dos fenômenos: pode-se tentar explicar por que o homem se desenvolve fisiologicamente; pode-se tentar entender o motivo que leva um corpo a cair; pode-se entender o que são os sons, as cores etc; em suma, pode-se falar do mundo físico terrestre, pois as causas podem ser sugeridas e investigadas. Em contrapartida, o que se pode falar do mundo celeste? Dada a distinção entre os mundos, e dado o procedimento metodológico instrumentalista, poucas coisas poderiam ser sustentadas realisticamente sobre o mundo celeste.

É nesse contexto caracterizado pela tese que o cosmo é composto de dois mundos distintos (céu e Terra) e pelo axioma platônico que deve ser entendido o conteúdo da carta de Kepler a Mästlin. O que Kepler apresenta nessa carta é uma pequena etapa do processo de rompimento com essa distinção e com o axioma platônico.

\section{Do GÍrGULo À OVAL}

A carta data de 14, de dezembro de 1604. Nessa época, é muito provável que Kepler estivesse trabalhando com sua hipótese de que a forma da órbita do planeta Marte é uma espécie de oval, visto que a forma circular e uniforme tinha sido posta em dúvida por Kepler porque não correspondia, quando testada, aos dados de Brahe e às exigências de uma astronomia física (cf. G.W., III, caps. 41 a 45 ). ${ }^{5}$ Em outros termos, a carta foi escrita quando Kepler estava entre a forma orbital circular e a elíptica, num meio termo, se assim podemos dizer, entre a concepção tradicional e as inovações que o levaram a mudar os enfoques epistemológico e metodológico na ciência astronômica. As razões que nos levam a acreditar nisso encontram-se em dois aspectos básicos da produção científica kepleriana.

Em primeiro lugar, a Astronomia nova apresenta uma peculiaridade interessante; ela é uma obra que expõe o desenvolvimento cronológico da investigação de Kepler

5 As referências às obras keplerianas, bem como às cartas, foram retiradas da edição de Max Caspar \& Walter von Dyck da obra completa de Kepler, Gesammelte Werke. Referiremos a essa edição por meio da abreviação G.W., seguida do número do volume em algarismos romanos e da indicação do capítulo ou do número das páginas em algarismos arábicos. 
OS PRIMÓRDIOS DA PRIMEIRA LEI DOS MOVIMENTOS PLANETÁRIOS...

e não apenas os resultados alcançados em sua forma final; Kepler apresenta os procedimentos, as etapas, pelas quais passou até obter as duas primeiras leis dos movimentos planetários. A importância disso é tão significativa que a segunda lei aparece (cf. G.W., III, cap. 40) antes da primeira lei (cf. G.W., III, cap. 58), e a relação das áreas só foi reconhecida como uma lei quando combinada com a lei da forma elíptica - a lei das áreas só se torna operante numa órbita elíptica, não podendo ser aplicada às órbitas circulares sem produzir discrepâncias com relação aos dados observacionais de Tycho Brahe. Assim, o relato contido na Astronomia nova indica que, durante o ano de 1604, Kepler trabalhou na crítica da órbita circular e uniforme, formulando novas hipóteses sobre o tipo de curva que de fato os planetas percorrem.

Em segundo lugar, a correspondência kepleriana também corrobora que Kepler trabalhava em 1604, com a hipótese da oval. As cartas escritas, principalmente para Mästlin e Fabrício, no ano de 1605, trazem informações importantes sobre os estágios desenvolvidos por Kepler em sua investigação teórica dos movimentos planetários, que, de certa forma, foi influenciada pela admissão de que a órbita real de Marte é uma espécie de oval. O pensamento de Kepler em astronomia é alicerçado em dois critérios básicos: o primeiro é que as hipóteses propostas para a composição dos movimentos planetários devem ser empiricamente testadas, sendo os dados observacionais de Brahe o principal componente para esses testes; o segundo reza que a astronomia deve ser elaborada tendo em vista os aspectos físicos e reais manifestos em seus fenômenos, e não meramente os instrumentais e matemáticos. Ora, algumas das cartas escritas por Kepler no final de 1604 e durante 1605 apontam justamente para a aplicação desses critérios. Assim, as órbitas circulares e uniformes não são corroboradas pelos dados de Brahe e, além disso, não há circularidade e uniformidade quando levamos em conta os aspectos físicos que se encontram nos movimentos celestes. Nesse sentido, é significativo o que Kepler escreve a Mästlin em 15 de março de 1605 :

No que concerne aos movimentos de Marte, vou explicar-me mais claramente ... As distâncias não estão como num círculo perfeito, mas como numa oval, da qual, após esforços infinitos, encontrei a representação ... A solução não será possível a não ser que investiguemos as causas que se encontram nas naturezas reais, ou seja: o corpo solar é circularmente magnético e gira sobre si mesmo, fazendo girar com ele o orbe de sua virtude ... Em contrapartida, os próprios corpos dos planetas são aptos a permanecer em repouso em qualquer lugar do mundo em que estejam localizados. Conseqüentemente, para que eles sejam movidos pelo Sol, é necessária a ação de uma força contrária, resultando que quando eles estiverem mais afastados do Sol, mover-se-ão mais lentamente e, quando mais próximos, mais rapidamente (G.W., XV, p. 171). 
Se a órbita não é circular, considera Kepler, então ela é uma curva fechada, uma espécie de oval que corresponde às exigências físicas: tratar os movimentos planetários tendo em vista o Sol real, isto é, o próprio corpo do Sol, visando, portanto, um tipo de explicação que determine a causa dos movimentos, a qual é, no caso, a ação da força magnética exercida pelo Sol sobre os planetas, conjuntamente com a resistência destes últimos (sua inércia natural, tomada como tendência a permanecer em repouso) a essa ação. Alguns meses depois, Kepler chega à representação matemática de sua oval: ela é, na verdade, uma elipse. Novamente, a correspondência nos indica mais esse avanço na direção da determinação da verdadeira órbita do planeta Marte. Numa carta a Fabrício, datada de 11 de outubro de 1605 , Kepler diz:

Vou dizer-vos agora os progressos que tenho feito acerca de meu planeta Marte. Como vi que, pela admissão de uma trajetória perfeitamente circular, as distâncias [de Marte ao Sol] são muito extensas, e que, nessas mesmas medidas, para minha elipse, que difere muito pouco da oval, elas são muito pequenas, tirei, muito justamente, a seguinte conclusão: o círculo e a elipse são figuras geométricas de mesmo gênero; elas pecam igualmente, mas em sentidos contrários, contra a verdade; portanto, a verdade se encontra no meio. Ora, entre duas figuras elípticas não se pode encontrar nada além de uma outra elipse. ... Essa é a verdade (G.W., XV, p. 247-8).

Assim, a forma verdadeira da órbita do planeta Marte ${ }^{6}$ é elíptica. É apenas a elipse que pode satisfazer os testes empíricos quando se consideram os aspectos naturais, físicos, envolvidos nos movimentos dos planetas; em particular quando se considera que o Sol é o centro físico dos movimentos planetários.

Mas esse resultado foi obtido, como dissemos, em 1605. Quando Kepler escreve a Mästlin, em dezembro de 1604 , ele estava a alguns passos dessa descoberta; foi justamente a impossibilidade do uso dos artifícios instrumentais do epiciclo e do deferente que lhe alertaram para a verdade: as órbitas planetárias não são nem circulares nem uniformes; e tampouco podem ser compostas de movimentos circulares e uniformes; a órbita de Marte é, de fato, uma curva achatada, uma curva oval, restando saber que tipo de oval descreve a órbita.

6 É óbvio que o argumento exposto na carta não prova que a órbita é elíptica; isso é apenas um recurso retórico para argumentar que a verdadeira forma da órbita do planeta não é um círculo, mas sim uma curva fechada, uma elipse. A prova de que a órbita é verdadeiramente elíptica encontra-se na Astronomia nova (cf. G.W. III, caps. 57 - 60). 
OS PRIMÓRDIOS DA PRIMEIRA LEI DOS MOVIMENTOS PLANETÁRIOS...

\section{A impossibiliddade do uso do epiGiGlo Gom Deferente}

O conteúdo do segundo parágrafo da carta traduzida trata diretamente dos usos técnicos e da impossibilidade deles corresponderem, quando analisados sob o ponto de vista da admissão do corpo físico do Sol como centro dos movimentos planetários, às observações astronômicas. Como vimos, Kepler, na época em que escreve a carta, apesar de já ter posto em dúvida que a hipótese da circularidade e uniformidade descreva a forma verdadeira da órbita de Marte, ainda utiliza os expedientes técnicos, como o epiciclo com deferente, de maneira que isso indica a necessidade do uso desses expedientes no processo de descoberta das leis, pois, apesar de não terem nenhuma função a partir do momento em que as leis são estabelecidas, mostraram-se indispensáveis para a descoberta da expressão da forma elíptica das órbitas dos planetas.

Kepler procura mostrar que as técnicas ligadas ao axioma da circularidade e uniformidade, quando aplicadas ao contexto das exigências físicas keplerianas (isto é, fundamentalmente, quando se consideram os movimentos com relação ao corpo do Sol enquanto centro físico e fonte dos movimentos) não são corroboradas pelos dados de Brahe, apresentando discrepância, ou "fuga" da circularidade e uniformidade.

Kepler encontrou o seguinte problema: por um lado, os dados de Brahe e a consideração do Sol como centro físico dos movimentos indicam que a órbita do planeta ingressa para os lados cerca de 900 partes em 152.500; por outro lado, a técnica do epiciclo com deferente, quando considerada a partir do

ASTRONOMIA NOVA

PHYSICA COELESTIS.

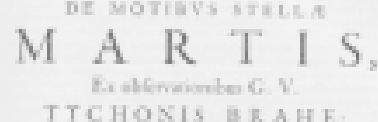

TYCHOXIS BR.AHE

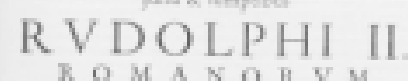

R $O$ M A N O It $\mathrm{V} M$

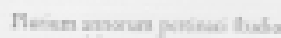

$10 A N N E$ KIPLERO

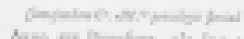

Frontispício da Astronomia nova, de 1609 .
Sol real, mostra um ingresso na ordem de 1.300 partes, tendo-se, portanto, uma diferença na ordem de 4,00 partes. Ora, isso indicará para Kepler, alguns meses depois, que o uso do epiciclo com deferente não expressa também, assim como a circularidade e a uniformidade, a verdadeira órbita do planeta Marte, sendo insuficiente o seu uso na astronomia.

O próprio relato da carta mostra que Kepler não sabia, nesse momento, como expressar corretamente os resultados obtidos, limitando-se a apresentar os problemas postos, quando se utiliza da técnica dos epiciclos. No capítulo 45 da Astronomia nova, escrito provavelmente durante a segunda metade de 1605 , Kepler organiza os dados e mostra mais coerentemente o problema. Na figura abaixo, que se encontra nesse capítulo 45, é possível apreciar os resultados a que Kepler chega, quando considera que o planeta perfaz movimentos segundo epiciclos: 


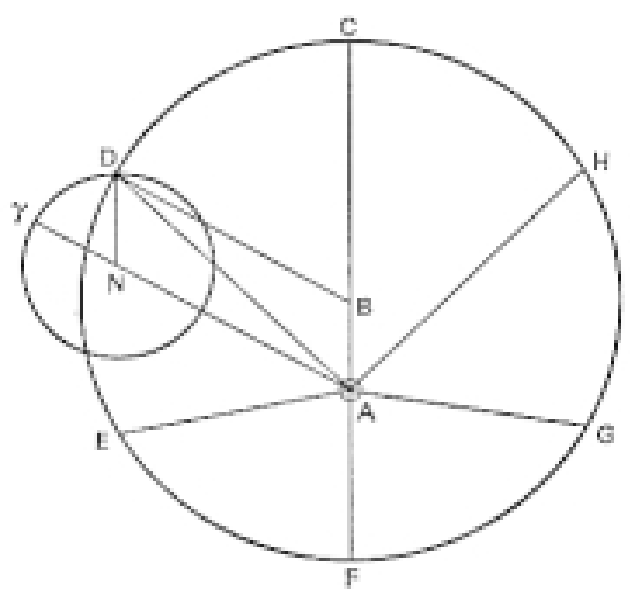

Figura que representa os movimentos em epiciclos, vistos a partir do Sol real (G.W., III, cap. 45).

Na figura, A é o Sol real, em torno do qual gira o planeta. CF é a linha das apsides que une o periélio $\mathrm{F}$ e o afélio $\mathrm{C}$. B é o centro do deferente; o círculo $\gamma \mathrm{D}$ é um movimento epicíclico com centro em N. A partir desses dados, pode-se fazer as seguintes construções:

(1) o centro $\mathrm{N}$ do epiciclo é mais rápido ou mais lento, quando o planeta está mais perto ou mais afastado do Sol, e o centro N estará sempre à mesma distância; (2) o planeta gira ao redor desse centro, um ponto fictício no qual não se encontra nenhuma causa física do movimento;

(3) além disso, suponhamos que a velocidade de rotação ao redor desse ponto seja proporcional à sua distância do Sol, a fim de manter o raio ND paralelo ao eixo das apsides CF.

Entretanto, quando tomamos essa construção e comparamos ao conjunto das observações de Brahe, deslocando o centro para o Sol físico, temos:

(a) admitindo-se que o planeta se move ao redor de $\mathrm{A}$ com velocidade angular igual à velocidade mediana no centro $\mathrm{N}$ do epiciclo, teremos que essa velocidade, no início do percurso (perto do afélio $\mathrm{C}$ ), será menor que a velocidade computada a partir do centro N;

(b) portanto, o ângulo $\gamma \mathrm{ND}$ será maior que o ângulo $\gamma \mathrm{AC}$;

(c) portanto, o raio ND não será paralelo a $\mathrm{CF}$, mas inclinado em direção a essa linha; e o planeta aparecerá na direção do ponto D;

(d) a situação será inversa na direção do periélio F, ou seja, a velocidade angular do planeta será maior que a do ponto N; 
OS PRIMÓRDIOS DA PRIMEIRA LEI DOS MOVIMENTOS PLANETÁRIOS...

(e) portanto,o planeta retardar-se-á sobre $\mathrm{N}$ e estará mais próximo de $\mathrm{F}$, do que se ele se movesse com uma velocidade igual a do ponto $\mathrm{N}$.

Esses resultados indicam que os movimentos computados a partir do epiciclo não conseguem representar a órbita em termos de movimentos circulares e uniformes, pois a órbita se achata nas longitudes medianas, isto é, fora dos pontos $\mathrm{C}$ e F, e o planeta apresenta variação de velocidade conforme se aproxima de $\mathrm{C}$ ou F. Isso é dado principalmente pela impossibilidade do raio ND manter-se paralelo à linha das apsides $\mathrm{CF}$ - quando computadas a partir de A; o raio ND, portanto, não se mantém constante, variando conforme o planeta se afasta ou se aproxima do Sol real A. Ora, isso se mostrará para Kepler mais à frente (cf. G.W., III, caps. 57 e 58) como a ação do Sol sobre o planeta. O Sol é o responsável físico, justamente, pela força emitida, que leva o planeta a ingressar nas longitudes medianas e se aproximar dos pontos na linha das apsides CF. Kepler substituirá os movimentos feitos pelos epiciclos por raios vetores que unem o planeta ao Sol, sendo que há uma espécie de movimentos de libração (oscilações desses raios vetores) que levam o planeta a alterar constantemente o movimento circular e uniforme para uma curva em forma elíptica.

Os problemas apresentados na representação dos movimentos por meio de epiciclos conduziram a duas possibilidades: quando se admite os epiciclos com deferentes (e, portanto, são satisfeitas as exigências de circularidade e uniformidade), então não se pode tomar como centro de movimentos o Sol real, pois isso é refutado pelos dados de Brahe; por outro lado, quando se quer construir uma astronomia física, isto é, considerar os movimentos tomando como centro o Sol físico, então os movimentos não são nem circulares nem uniformes, tampouco ovais, e de uma forma mais precisa, são elípticos. Kepler fica com a segunda opção.

A diferença básica entre Kepler e a tradição de sua época é que esta expressaria os movimentos do epiciclo a partir do ponto B (um ponto que não representa o corpo físico do Sol, mas fictício - e que, portanto, pode estar em qualquer parte da linha CF, de maneira a adequar os dados ao epiciclo), rejeitando o uso do ponto A (do Sol real). ${ }^{7}$ Kepler, por outro lado, computa a partir de A, o que indica a impossibilidade do movimento epicíclico corresponder às observações de Brahe.

Subseqüentemente, o epiciclo com deferente será rejeitado (cf. G.W., III, caps. 57 e 58), tendo-se, em seu lugar, que os movimentos são elípticos e o Sol-ou seu corpo físico - ocupa um dos focos da elipse.

7 O peso do uso dos artifícios matemáticos para computar os movimentos como circulares e uniformes era tão expressivo na astronomia da época de Kepler que até mesmo Copérnico não tratou os movimentos a partir do Sol real, isto é, as órbitas dos planetas não tinham como centro o corpo físico do Sol, mas um ponto matemático. 
Nesse sentido, a carta a Mästlin de 14, de dezembro de 1604 é um relato de uma das principais etapas da astronomia física de Kepler. Sua importância está em ser um documento que relata uma das dificuldades centrais para a manutenção do axioma platônico na astronomia e na cosmologia.

Claudemir Roque Tosato
Pesquisador do Projeto Temático
"Estudos de filosofia e história da ciência” da FAPESP,
pós-doutorando do Departamento de Filosofia
da Universidade de São Paulo.
toclare@uol.com.br

REFERÊNGIAS BIBLIOGRÁFIGAS

\section{Primárias}

KEPLER, J. Gesammelte Werke. 17 vols. Ed. de M. Caspar \& W. von Dyck. Munique, C. H. Beck'sche Verlagsbuchhandlung, 1937-1959. (G.W.)

. Astronomia nova. In: M. CASPAR \& W. von DYCK (eds.). Gesammelte Werke. Vol. III. Munique, C.

H. Beck'sche Verlagsbuchhandlung, 1937 .

. Correspondência, 1604-1607. In: M. CASPAR \& W. von DYCK (eds.). Gesammelte Werke. Vol. XV.

Munique, C. H. Beck'sche Verlagsbuchhandlung, 1951.

\section{Secundárias}

APPLEBAUM, W. “Keplerian astronomy after Kepler: researches and problems”. In: History of Science,

34,1996, p. $45^{1-}{ }^{-5} 4$.

COHEN, I. B. O nascimento de uma nova física. São Paulo, Edart, 1967.

HANSON, N. R. Constelaciones y conjeturas. Madri, Alianza Universidad, 1985.

KOESTLER, A. Os sonâmbulos. São Paulo, Ibrasa, 1961.

MOURÃO, R. R. F. Dicionário enciclopédico de astronomia e astronáutica. Rio de Janeiro, Nova Fronteira, 1995 . 